Please do not remove this page

RMIT

UNIVERSITY

\title{
Characterising fibre compression fracture toughness of composites using bearing tests
}

Chishti, Maajid; Wang, Chun; Thomson, Rodney; Orifici, Adrian

https://researchrepository.rmit.edu.au/esploro/outputs/9921859163501341/filesAndLinks?institution=61RMIT_INST\&index=null

Chishti, M., Wang, C., Thomson, R., \& Orifici, A. (2012). Characterising fibre compression fracture toughness of composites using bearing tests. Composites Part A: Applied Science and Manufacturing, 43(10), 1775-1782. https://doi.org/10.1016/j.compositesa.2012.05.005

Document Version: Accepted Manuscript

Published Version: https://doi.org/10.1016/j.compositesa.2012.05.005

Repository homepage: https://researchrepository.rmit.edu.au

(c) 2012 Elsevier Ltd. All rights reserved

Downloaded On 2023/04/26 22:42:49 +1000

Please do not remove this page 
Thank you for downloading this document from the RMIT Research Repository.

The RMIT Research Repository is an open access database showcasing the research outputs of RMIT University researchers.

RMIT Research Repository: http://researchbank.rmit.edu.au/

\section{Citation:}

Chishti, M, Wang, C, Thomson, R and Orifici, A 2012, 'Characterising fibre compression fracture toughness of composites using bearing tests', Composites Part A: Applied Science and Manufacturing, vol. 43, no. 10, pp. 1775-1782.

See this record in the RMIT Research Repository at:

http://researchbank.rmit.edu.au/view/rmit:20567

Version: Accepted Manuscript

Copyright Statement: (c) 2012 Elsevier Ltd. All rights reserved

Link to Published Version:

http://dx.doi.org/10.1016/j.compositesa.2012.05.005 


\title{
Characterising Fibre Compression Fracture Toughness of Composites using Bearing Tests
}

\author{
Maajid Chishti $^{\text {a }}$, Chun H. Wang ${ }^{\text {a, }}$, Rodney S. Thomson ${ }^{\text {b }}$, Adrian C. Orifici ${ }^{\text {a, }}{ }^{,}$ \\ ${ }^{\mathrm{a}}$ Sir Lawrence Wackett Aerospace Research Centre, \\ School of Aerospace, Mechanical and Manufacturing Engineering, RMIT University \\ GPO Box 2476, Melbourne, Victoria 3001, Australia \\ * corresponding author: adrian.orifici@rmit.edu.au, fax +6139925 6108 \\ ${ }^{\mathrm{b}}$ Cooperative Research Centre for Advanced Composite Structures Ltd, \\ 506 Lorimer Street, Fishermans Bend, Victoria 3207, Australia
}

\begin{abstract}
In this paper we propose the use of a bearing test with a coupled experimentalnumerical approach to characterise the critical strain energy release rate, or "fracture toughness", for fibre compression failure in bearing. This property is used in continuum damage mechanics (CDM) approaches for progressive failure analysis of composite laminates. In the proposed approach, experimental results for a standard bearing test are used to calibrate the fracture toughness with a progressive failure analysis using a CDM damage model. The approach is demonstrated for a plain weave carbon/epoxy material using the CDM damage model available in a commercial finite element package (Abaqus). The results indicate that the bearing test method provides a simple and convenient means of quantifying fibre compression fracture toughness. Analysis results applying the
\end{abstract}


characterised value show good comparison with experimental results, and confirm the value of the bearing test as part of a novel material characterisation technique.

Keywords: A. Lamina/ply. B. Fracture toughness; C. Damage mechanics; D. Mechanical testing.

\section{Introduction}

Bearing failure of composite bolted joints is predominately a local compressive failure mode that occurs due to contact between the bolt and the composite laminates, and is a desired failure mode in aerospace applications due to its progressive and noncatastrophic nature. For fibre-reinforced composite laminates, bearing failure involves damage modes in the vicinity of the hole that include tensile, compressive and shear failure of fibres and matrix as well as delamination [1]. As such, the energy dissipated during the bearing damage process is the result of a combination of multiple failure modes, which includes fibre micro-buckling, matrix cracking and delamination [2, 3].

The critical strain energy release rate, or "fracture toughness" associated with fibre compression failure is a critical property for characterising the progressive failure of composites. This fracture toughness incorporates the energy dissipating mechanisms associated with in-plane fibre fracture, corresponding to an in-plane crack propagating perpendicular to the fibre direction. This property characterises the energy released per area of crack surface created, and has been required as an input parameter in continuum damage mechanics (CDM) analysis approaches proposed by several authors [4, 5]. 
Currently, no standards exist for determining the fracture toughness associated with fibre compression failure. The compact compression specimen has been used by several authors [6-8], and involves an edge-notched specimen loaded in compression. Detailed Cscan and fractographic analysis of the compact compression specimen in Ref. [8] showed that kink-band formation and delamination both occurred and absorbed considerable energy. This highlights the difficulty in isolating individual damage mechanisms as part of a compression failure process.

More significantly, in Ref. [9] the authors found that different specimen configurations for characterising fibre failure fracture toughness determined significantly different values for the same laminate. This suggests that each specimen configuration contains a unique combination of individual damage mechanisms contributing to the overall failure process. The dependence of fracture energy and fracture mode on specimen configuration has also been reported by other researchers $[10,11]$. With regards to bearing failure, it is clear that the interaction of fibre and matrix failure mechanisms and the influence of delamination are considerably different from notch-based specimens such as the compact compression configuration. As such, an appropriate specimen configuration to determine fracture toughness should display a failure process as close as possible to the specimen configuration to which the toughness will be subsequently applied.

The American Society for Testing and Materials (ASTM) standard for bearing test specimens D5961 [12] defines guidelines for joint dimensions to promote bearing failure in polymer matrix composite laminates, summarised in Figure 1. The standard provides guidelines for the use of balanced and symmetric multi-directional stacking sequences 
using quasi-isotropic directions with total laminate thickness between $3 \mathrm{~mm}$ to $5 \mathrm{~mm}$. The standard also presents guidelines on the test procedure and data reduction methods for determining bearing response parameters. However, the bearing parameters defined in this standard are joint-specific design parameters, such as the ultimate joint load or the load associated with an arbitrary amount of bearing displacement, and do not relate to material parameters such as strength and fracture toughness.

In this work, the use of a bearing test specimen is proposed for the characterisation of fibre compression fracture toughness for bearing applications. The use of experimental bearing test results coupled with numerical analysis using a CDM damage model is proposed as a technique for characterising the fibre compression fracture toughness. The application of the characterised fracture toughness for progressive failure analysis of specimens involving different laminates, hole geometries and other bolted joint parameters is demonstrated.

\section{Characterisation}

\subsection{Methodology}

A coupled experimental-numerical approach is proposed for characterisation of the fibre compression fracture toughness of polymer composite ply materials undergoing bearing damage. In the experimental investigation, a bearing test specimen is loaded to experience bearing damage, and the kinematic behaviour of the specimen recorded. A numerical analysis is then conducted using an analysis methodology in which the fibre compression fracture toughness is a required input parameter. After ensuring that the response of the specimen prior to the onset of bearing damage is well captured, an 
appropriate fracture toughness can be determined through parametric investigation in comparison with the experimental results.

\subsection{Bearing test specimens}

The characterisation process described above was applied to determine the fibre compression fracture toughness of a plain weave carbon/epoxy T300/970 pre-preg ply (nominal ply thickness $0.22 \mathrm{~mm}$ ). A bearing test specimen was designed according to the recommendations to promote bearing failure in ASTM standard D5961 [12], and is shown in Figure 2 and Table 1. In the bearing test, a single laminate with a straight-edge circular hole had a rigid pin placed in the hole, with the laminate and pin loaded in tension to promote bearing failure at the hole edge.

\subsection{Experimental setup}

The experimental setup for the bearing test is shown in Figure 3, where a steel pin was placed through the hole and attached to a support structure. The support structure was gripped and held whilst the specimen was gripped and loaded in tension. An extensometer was placed between the support structure and a tab bonded on the specimen. The bearing test rig did not allow damaged material to accumulate in the pin region during testing. This is seen in Figure 3, where a gap and a Teflon layer were included between the laminate and the test rig on either side. A $100 \mathrm{kN}$ MTS test machine was used, and the specimens were loaded in displacement control at $0.5 \mathrm{~mm} / \mathrm{min}$ until the maximum load was reached. The maximum load and overall joint behaviour were first identified from a preliminary test with a large amount of loading displacement applied. 


\subsection{Numerical modelling}

For the numerical analysis, the commercial finite element solver Abaqus/Explicit 6.9 [13] was used, which has a CDM damage model for in-plane composite ply failure. In this damage model, four damage modes associated with tension and compression failure of the fibre and matrix are monitored and used to trigger property reductions that are controlled by the fracture toughness in each modes. This damage model is only applicable with elements that use a plane-stress formulation, which includes both standard 4-node shells and 8-node "continuum" shells [5]. Further, this damage model is implemented with failure criteria developed for uni-directional tape materials only. Despite these limitations, it was considered that the accuracy of the model was still suitable to capture overall specimen behaviour and demonstrate the proposed characterisation approach. This aspect is discussed further in following sections. The application of a CDM damage model to bearing loads of bolted specimens has been successfully demonstrated by Camanho et al. [14] using the Abaqus model applied in this work, or Hühne et al. [15] using a similar model, in which the aspects such as kink band formation and application with fibre compression failure were discussed.

In the numerical models, each fabric ply was modelled as two uni-directional plies that represented the in-plane stiffness and strength of the woven ply. For example, the $[0,45]_{4 \mathrm{~S}}$ laminate of fabric plies was modelled as a $[0,90,45,-45]_{4 \mathrm{~S}}$ laminate of unidirectional plies. Each uni-directional ply was modelled as a layer of continuum shells, so that the 16-ply laminate was modelled using 32 elements in the through-thickness direction. This approach was taken so that the Abaqus uni-directional ply damage model could be 
applied, and has been applied by other researchers modelling stiffness and strength of fabric ply composites [16].

The mesh and boundary conditions are shown in Figure 4. The in-plane mesh density was determined using mesh sensitivity investigations, which are not included here for brevity. Element sizes of less than $1 \mathrm{~mm}$ around the hole were used, which was smaller than the maximum element size of $14 \mathrm{~mm}$ calculated based on the limiting case where the fracture toughness is equated to the elastic energy at damage initiation $[4,17]$. The pin was modelled using rigid elements. A mass scaling factor of 100 was applied, and was determined as suitable using parametric studies. The transverse shear stiffness was not defined but was determined using Abaqus' internal default procedures [13], which are based on the transverse Young's moduli $G_{13}$ and $G_{23}$ given in Table 2. The $\alpha$ parameter in the Abaqus damage model used was 1.0, which includes the effect of shear in the fibre tensile failure criterion [13]. Further detail on the numerical modelling is provided in other references $[18,19]$.

For the uni-directional ply properties, all constants were first estimated using fibre and matrix properties and the procedures in Ref. [20]. Following this, the numerical analysis results were compared to the experimental bearing test results in order to calibrate the stiffness and strength properties. This process is illustrated in the results shown in Figure 5, which compares the experiment and numerical ("FE") predictions using estimated and calibrated material properties. 
The calibration of ply properties was conducted in a largely ad hoc nature, though based on a series of targeted parametric studies. This process was also performed in conjunction with assessing the effect of the calibrated properties on the damage progression. In this respect, the over-prediction of the peak load of the experimental bearing test, as shown in Figure 5, was considered acceptable in light of the close correlation with the experimental failure loads of the specimens during damage progression. Furthermore, reducing the strength values to match the experimental bearing test resulted in significantly poorer predictions for both the bearing test and the single-lap joints presented in the following section. Although outside the scope of the current work, the calibration process could be further developed to incorporate a range of different approaches, such as taking material data from standardised tests and applying an optimisation procedure for parameter identification.

The present method of determining material properties allows for the isolation of the fracture toughness in subsequent calibration considering the region of bearing damage. The estimated and calibrated material property sets are given in Table 2, where $E, G$ are the elastic moduli, $v$ are Poisson ratios, $X, Y, S$ are ply strengths in the longitudinal, transverse and shear directions respectively, subscripts 1,2,3 refer to fibre, in-plane transverse and through-thickness directions, and subscripts $T$ and $C$ refer to tension and compression.

\subsection{Results}

The numerical model was used to determine characterised fracture toughness values, by comparison with the experimental bearing test results for the entire load history. The fracture toughness values were first estimated using the values reported in Ref. [8]. 
Following this, the fracture toughness values were calibrated using the experimental bearing test results. Given the nature of the bearing test configuration, the progressive failure predictions were dominated by the fracture toughness for fibre failure in compression, $G_{f c}$. A range of analyses were conducted with varying $G_{f c}$ values, where the values reported in Ref. [8] were investigated at $90 \%, 80 \%, 70 \%$, etc., of their reported values. The results of the investigation are summarised in Figure 6 and Figure 7, where Figure 6 shows the load-displacement results and Figure 7 plots the first peak load (indicative of damage onset) against the average load following the first peak to an applied displacement of $1.2 \mathrm{~mm}$ (indicative of damage progression) for all simulations in comparison with experiment. From these results, a $G_{f c}$ value of $55 \mathrm{~kJ} / \mathrm{mm}^{2}$ was found to give closest comparison with the experimental bearing test results. The calibrated $G_{f c}$ value was used to scale the fibre tension fracture toughness $G_{f t}$ value. All fracture toughness values are summarised in Table 3, where subscripts $f$ and $m$ refer to fibre and matrix properties, and subscripts $t$ and $c$ refer to tension and compression properties.

Although a detailed study of both experimental and numerical damage modes was conducted, the profile of damage modes was not used as part of the calibration process. This was because the experimental and numerical damage modes were not distinguishable to a level of fidelity suitable for calibration purposes. The experimental and numerical results are presented in detail in other publications, which cover characterisation of the experimental damage modes [21] and comparison with numerical predictions [19]. The experimental specimens showed a complex bearing crush front ahead of the hole that was dominated by fibre compression failure, with delamination and matrix damage also present. 
The numerical results predicted a zone of fibre compression failure at the contact side of the hole, with matrix damage, and delamination shown to have only minor influence. However, the complexity of the experimental damage zone, in addition to the coarse and approximate nature of the numerical damage modes, meant that consideration of the damage modes did not provide any improvement to the calibration process. Some experimental and numerical results with regards to damage mode are presented in the following section for single-lap joints, though the reader is referred to the referenced publications for more detail and comparison with regards to damage mode.

\section{Application}

\subsection{Single-lap countersunk joint specimens}

The fibre compression fracture toughness characterised in the previous section was applied to the progressive failure analysis of a different batch of test specimens. Single-lap joint specimens with countersunk bolts were investigated, and are summarised in Figure 8 and Table 1. In the single-lap joint test, two laminates were bolted together and loaded on the edge of each laminate in tension. The specimens were designed according to the recommendations to promote bearing failure in ASTM standard D5961 [12]. The single-lap joint specimens used the same plain weave carbon/epoxy T300/970 pre-preg material as was characterised using the bearing tests.

Variations in the countersunk bolt parameters were investigated, which included different levels of bolt torque (BT), bolt clearance (CL), and countersink height to laminate thickness ratio $h / t(\mathrm{HT})$. Each parameter was tested at three levels as summarised in Table 
4. Clearance was introduced by increasing the diameter of the straight-edge portion of the bolt hole only.

\subsection{Experimental setup}

The experimental setup for the single-lap joints is shown in Figure 9. An extensometer was placed between tabs and strain gauges (SGs) were also used as shown in Figure 8. Bolt torque was introduced using a calibrated torque wrench. The specimens were loaded in displacement control at $0.5 \mathrm{~mm} / \mathrm{min}$ in a $100 \mathrm{kN}$ MTS test machine until the maximum load was reached. No washers were used on any of the bolts.

\subsection{Numerical modelling}

Models were created in Abaqus/Explicit 6.9 [13] for the single-lap joint configurations, using a modelling strategy based on the one discussed previously for the bearing tests. The in-plane mesh density was the same as the bearing tests (Figure 4(a)), and was confirmed as appropriate using mesh sensitivity investigations. The boundary conditions and complete model are shown in Figure 10. In the through-thickness direction, the models used 4 elements for the lower laminate and between 2 and 4 elements for the upper laminate depending on the hole geometry. The bolt-nut assembly was modelled using rigid elements. Frictional contact was introduced at all contactable interfaces (including between laminates and contact with the bolt-nut assembly), with a friction coefficient of 0.2 taken from recommendations in literature [22]. Bolt torque was introduced in pre-loading steps using the displacement, where a displacement of $1.81 \mu \mathrm{m}$ was found to represent the torque at $2.103 \mathrm{~N} \mathrm{~m}$. The CDM damage model for in-plane ply failure of fibre-reinforced composites was applied, with the material properties as given in Table 2 and Table 3. 
Delamination was not modelled in this investigation, though has been studied in separate investigations and shown to have minimal influence on the specimen behaviour [19].

\subsection{Results}

Comparison between the analysis methodology with the calibrated fracture toughness values and the experimental results are shown in Figure 11, Figure 12 and Figure 13, where the applied load or applied (far-field) stress is plotted against the extensometer displacement. In these figures, the experimental results are shown for one specimen of each configuration as representative of the average of the three repetitions. These results illustrate that the calibrated analysis methodology captured the load-carrying capability of the joints reasonably well across all joint configurations. This is despite the changes in bolt torque, clearance and countersink height ratio, and the fact that the calibration was performed on specimens with straight-edge holes whilst the joints contained tapered hole sections. A detailed study of the experimental results in terms of the damage progression and effect of the countersink geometry is presented in a separate publication [21].

A comparison between the in-plane and through-thickness damage profiles of experimental specimens and numerical analyses is presented in Figure 14 and Figure 15. These results show that the analysis methodology was capable of predicting the overall damage profile, though the complex damage patterns seen in the experiments were not able to be captured. The comparison is also limited by the use of only two and four elements through the thickness in the upper and lower laminates respectively, and the method of plotting the maximum damage index in each element. Despite these limitations, the results indicate that the use of fracture toughness values calibrated from the bearing test allows for 
the detailed investigation of damage progression in countersunk joints with numerical analysis. Detailed investigation of the damage progression, in particular a detailed study of the numerical analysis, is presented in other references $[18,19]$.

\section{Discussion}

The results presented demonstrate the feasibility of using the bearing test configuration to characterise fibre fracture toughness in compression for bearing damage. Considering the experimental results for the bearing test in Figure 6, the load-displacement profile shows a large non-linear region and a sustained and increasing load with increasing damage. This profile is a result of the progressive nature of the bearing failure process, in which a local crushed zone forms around the hole and the laminate is capable of carrying increased load. Such a profile is attractive from the perspective of characterising fracture toughness, as the behaviour of the specimen is more dependent on the damage progression and the energy absorbed in failure. In contrast, configurations that exhibit a catastrophic failure process, such as the open hole tension specimen, can show only a weak dependence on the fracture toughness $[23,24]$, and be challenging for material characterisation.

The numerical analysis methodology applied in this work was selected to demonstrate the proposed characterisation approach using a commercially available finite element package. In this respect, the analysis was limited by the available models and capabilities of the software, which included a damage model for only uni-directional tape materials, and the capability to apply this with only plane stress elements. The use of two uni-directional plies to represent a woven fabric layer is only approximate, and does not capture effects such as fibre undulation and fabric-specific damage modes. The use of 
calibration with the bearing test experiment ensured that the approximate approach was able to represent the stiffness and strength of the fabric ply. It is expected that improved predictions of specimen behaviour could be achieved by improved damage models, such as those presented by other authors $[4,16]$. Further improvements could be made by an increased focus on the initial ply properties, such as through the use of material data from standardised tests or an optimisation procedure for parameter identification. Despite this, the coupled experimental-numerical procedure demonstrated in this work presents a novel solution to the issue of characterising fibre fracture toughness for the complex case of bearing damage.

\section{Conclusion}

In this work, the bearing test is employed to characterise the fibre compression fracture toughness using a coupled experimental-numerical approach. The characterisation approach involves the application of a CDM damage model dependent on the fracture toughness, and calibration to match experimental kinematic behaviour. This characterisation approach was applied to determine a calibrated fracture toughness for a plain weave carbon/epoxy ply material. The characterised fracture toughness was demonstrated for the analysis of single-lap countersunk composite joints, which involved variations in hole geometry and other joint parameters. The bearing test and coupled experimental-numerical approach was shown to provide a suitable technique for obtaining the compression fracture toughness of composite laminates. The calibrated fracture toughness was shown to be suitable for predicting the load-carrying capabilities of the composite laminate across variations in bolt torque, clearance and countersink height ratio. 
The progressive nature of the bearing test load-displacement profile is attractive from a material characterisation perspective.

\section{Acknowledgements}

The authors acknowledge the financial support provided by the Australian

Postgraduate Award. The technical support of Mr Peter Tkatchyk (RMIT University) and Mr Daniel Bitton (CRC-ACS) is also kindly acknowledged. The computing facilities provided by the Victorian Partnership for Advanced Computing (VPAC) and RMIT-HPC are also acknowledged. 


\section{References}

[1] Xiao Y, Wang W, Takao Y, Ishikawa T. The effective friction coefficient of a laminate composite, and analysis of pin-loaded plates. Journal of Composite Materials. 2000;34:6987.

[2] Wang HS, Hung CL, Chang FK. Bearing failure of bolted composite joints. Part I:

Experimental characterisation. Journal of Composite Materials. 1996;30:1284-313.

[3] Camanho PP, Bowron S, Matthews FL. Failure mechanisms in bolted CFRP. Journal of Reinforced Plastics and Composites. 1998;17:205-33.

[4] Maimì P, Camanho PP, Mayugo JA, Dàvila CG. A continuum damage model for composite laminates: Part II - Computational implementation and validation. Mechanics of Materials. 2007;39:909-19.

[5] Lapczyk I, Hurtado JA. Progressive damage modeling in fiber-reinforced materials. Composites Part A: Applied Science and Manufacturing. 2007;38(11):2333-41.

[6] Ratcliffe JG, Jackson WC, J S. Compression strength prediction of impact-damaged composite sandwich panels. American Helicopter Society 60th Annual Form. Baltimore, MD, USA, 7-10 June, 2004.

[7] Jackson WC, Ratcliffe JG. Measurement of fracture energy for kink-band growth in sandwich specimens. Composites Testing and Model Identification. Bristol, UK, 21-23 September, 2004.

[8] Pinho ST, Robinson P, Iannucci L. Fracture toughness of the tensile and compressive fibre failure modes in laminated composites. Composites Science and Technology. 2006;66(13):2069-79. 
[9] Harris CE, Morris DH. A comparison of the fracture behaviour of thick laminated composites utilizing compact tension, three-point bend, and center-cracked tension specimens. Fracture Mechanics. 1986;17:124-35.

[10] Reedy ED. On the specimen dependence of unidirectional boron/aluminum fracture toughness. Journal of Composite Material Supplement. 1980;14:118-31.

[11] Shih TT, Logsdon WA. Fracture behavior of thick-section graphite/epoxy composite. Fracture Mechanics: Thirteenth Conference, ASTM STP 743: American Society for Testing and Materials, PA, USA; 1981.

[12] ASTM D5961, Standard test method for bearing response of polymer matrix composite laminates. American Society for Testing and Materials; 2007.

[13] Abaqus ${ }^{\circledR} 6.9$ Documentation. Providence, RI, USA: Dassault Systèmes Simulia Corporation; 2010.

[14] Camanho PP, Fink A, Obst A, Pimenta S. Hybrid titanium-CFRP laminates for highperformance bolted joints. Composites Part A: Applied Science and Manufacturing. 2009;40:1826-37.

[15] Hühne C, Zerbst A-K, Kuhlmann G, Steenbock C, Rolfes R. Progressive damage analysis of composite bolted joints with liquid shim layers using constant and continuous degradation models. Composite Structures. 2010;92:189-200.

[16] Raju IS, Foye RL, Awa VS. A review of analytical methods for fabric and textile composites. In: Reddy JN, Krishna Murthy AV, editors. Composite Structures - Testing, Analysis and Design: Springer - Verlag, NY, USA.; 1992.

[17] Bazant ZP, Jirasek M. Nonlocal integral formulations of plasticity and damage: Survey of progress. Journal of Engineering Mechanics. 2002;128(11):1119-49. 
[18] Chishti M, Wang CH, Thomson RS, Orifici AC. Progressive damage in single lap countersunk composite joints. 9th World Congress on Computational Mechanics and 4th Asian Pacific Congress on Computational Mechanics. Sydney, Australia, 19-23 July, 2010. [19] Chishti M, Wang CH, Thomson RS, Orifici AC. Numerical investigation of damage progression and strength of countersunk composite joints. Composite Structures. 2012;94:643-53.

[20] Chamis CC. Simplified composite micromechanics equation for mechanical, thermal and moisture-related properties. In: Weeton JW, Peters DM, Thomas KL, editors. Engineers Guide to Composite Materials: ASM International, OH, USA; 1987. [21] Chishti M, Wang CH, Thomson RS, Orifici AC. Experimental investigation of damage progression and strength of countersunk composite joints. Composite Structures. 2012;94:865-73.

[22] Tserpes KI, Papanikos P, Kermanidis T. A three-dimensional progressive damage model for bolted joints in composite laminates subjected to tensile loading. Fatigue \& Fracture of Engineering Materials and Structures. 2001;24:663-75.

[23] Gunnion AJ, Wang CH, Orifici AC. Progressive failure modelling of composite laminates containing tapered holes. 4th International Conference on Composite Testing and Model Identification. Dayton, Ohio, USA, 20-22 October, 2008.

[24] Wang CH, Gunnion AG, Orifici AC, Rider A. Residual strength of composite laminates containing scarfed and straight-sided holes. Composites Part A: Applied Science and Manufacturing. 2011;42:1951-61. 


\section{Figure Captions}

Figure 1: Specimen design guidelines to promote bearing failure (adapted from Ref. [12])

Figure 2: Bearing test specimen dimensions $(\mathrm{mm})$ and strain gauge location

Figure 3: Bearing test experimental setup

Figure 4: Bearing test. (a) In-plane mesh (b) Boundary conditions

Figure 5: Calibration of ply properties using bearing test results up to bearing damage initiation

Figure 6: Bearing test, experiment and numerical with varying fibre compression fracture toughness $(\mathrm{kJ} / \mathrm{mm} 2)$

Figure 8: Countersunk joint dimensions $(\mathrm{mm})$, strain gauge locations and extensometer tabs

Figure 9: Experimental setup for the single-lap countersunk joints, joint region shown Figure 10: Single-lap joint. (a) Boundary conditions. (b) Assembled model. Figure 11: Single-lap joints, variation in bolt torque, experimental and numerical results Figure 12: Single-lap joints, variation in clearance, experimental and numerical results Figure 13: Single-lap joints, variation in countersink height ratio, experimental and numerical results

Figure 14: Single-lap joint (BT2, CL1, HT2) following ultimate load. (a) Experiment (b) Numerical model, deformed mesh

Figure 15: Single-lap joint (BT2, CL1, HT2) following ultimate load, cross-section at hole edge along specimen centreline. Left: Upper laminate. Right: Lower laminate. (a) Experiment (b) Numerical model, fibre compressive failure maximum damage index 
Table 1: Specimen dimensions (mm)

\begin{tabular}{|l|l|l|l|l|}
\hline & $t$ & Layup & $D$ & $A$ \\
\hline Bearing & 3.52 & {$[0,45]_{4 \mathrm{~S}}$} & 6.35 & $\mathrm{n} / \mathrm{a}$ \\
\hline BT (all) & 3.52 & {$[0,45]_{4 \mathrm{~S}}$} & 4.76 & 9.56 \\
\hline CL (all) & 3.52 & {$[0,45]_{4 \mathrm{~S}}$} & 4.76 & 9.56 \\
\hline HT1 & 3.08 & {$\left[(0,45)_{3}, 0\right]_{\mathrm{S}}$} & 4.76 & 9.56 \\
\hline HT2 & 3.52 & {$[0,45]_{4 \mathrm{~S}}$} & 4.76 & 9.56 \\
\hline HT3 & 3.52 & {$[0,45]_{4 \mathrm{~S}}$} & 6.35 & 12.71 \\
\hline
\end{tabular}


Table 2: Elastic material properties for the UD ply

\begin{tabular}{|l|l|l|}
\hline Property & Estimated & Calibrated \\
\hline$E_{11}(\mathrm{GPa})$ & 138 & 84.7 \\
\hline$E_{22}(\mathrm{GPa})$ & 8.42 & 5.22 \\
\hline$G_{12}(\mathrm{GPa})$ & 3.93 & 2.41 \\
\hline$G_{13}(\mathrm{GPa})$ & 3.93 & 2.41 \\
\hline$G_{23}(\mathrm{GPa})$ & 3.03 & 1.88 \\
\hline$v_{12}$ & 0.257 & 0.3 \\
\hline$v_{13}$ & 0.257 & 0.3 \\
\hline$v_{23}$ & 0.387 & 0.381 \\
\hline$X_{T}(\mathrm{MPa})$ & 1496 & 1009 \\
\hline$X_{C}(\mathrm{MPa})$ & 1026 & 865 \\
\hline$Y_{T}(\mathrm{MPa})$ & 90 & 69 \\
\hline$Y_{C}(\mathrm{MPa})$ & 211 & 188 \\
\hline$S_{12}(\mathrm{MPa})$ & 77 & 69 \\
\hline$S_{13}(\mathrm{MPa})$ & 1.6 & \\
\hline$S_{23}(\mathrm{MPa})$ & & \\
\hline$\rho\left(\mathrm{g} / \mathrm{cm}{ }^{3}\right)$ & & \\
\hline
\end{tabular}


Table 3: Fracture toughness values for the UD ply

\begin{tabular}{|l|l|l|}
\hline Property & Estimated & Calibrated \\
\hline$G_{f t}\left(\mathrm{~kJ} / \mathrm{mm}^{2}\right)$ & 91 & 64 \\
\hline$G_{f c}\left(\mathrm{~kJ} / \mathrm{mm}^{2}\right)$ & 79 & 55 \\
\hline$G_{m t}\left(\mathrm{~kJ} / \mathrm{mm}^{2}\right)$ & 0.15 & 0.15 \\
\hline$G_{m c}\left(\mathrm{~kJ} / \mathrm{mm}^{2}\right)$ & 0.45 & 0.45 \\
\hline
\end{tabular}

Table 4: Single-lap joint

\begin{tabular}{|l|l|l|l|l|}
\hline & Bolt torque $(\mathrm{N} \mathrm{m})$ & Clearance $(\mu \mathrm{m})$ & $h / t$ & Number of specimens* \\
\hline BT1 & 0 (finger tight) & 0 & 0.56 & 3 \\
\hline BT2 & 2.103 & 0 & 0.56 & 3 \\
\hline BT3 & 4.206 & 0 & 0.56 & 3 \\
\hline CL1 & 2.103 & 0 & 0.56 & 3 \\
\hline CL2 & 2.103 & 240 & 0.56 & 3 \\
\hline CL3 & 2.103 & 440 & 0.56 & 3 \\
\hline HT2 & 2.103 & 0 & 0.56 & 3 \\
\hline HT1 & 2.103 & 0 & 0.64 & 3 \\
\hline HT3 & 2.103 & 0 & 0.76 & 3 \\
\hline
\end{tabular}

* BT2, CL1 and HT2 all represent the same configuration and the same specimens 


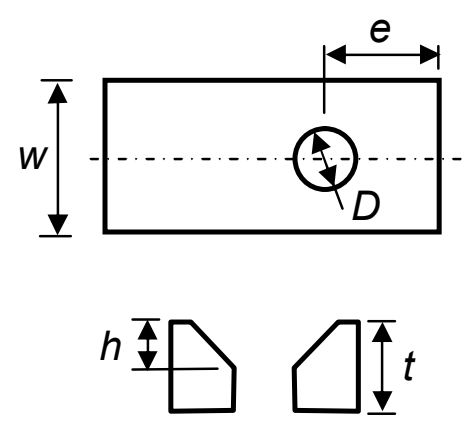

$$
\begin{gathered}
\frac{w}{D}>4 \\
\frac{e}{D}>3 \\
1.5 \leq \frac{D}{t} \leq 3.0 \\
0 \leq \frac{h}{t} \leq 0.7
\end{gathered}
$$

Figure 1: Specimen design guidelines to promote bearing failure (adapted from Ref. [12])

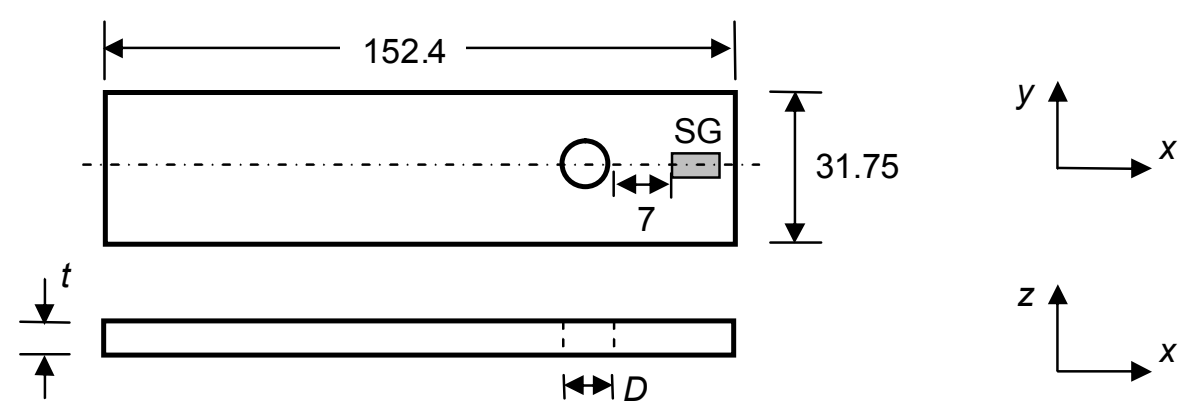

Figure 2: Bearing test specimen dimensions $(\mathrm{mm})$ and strain gauge location 


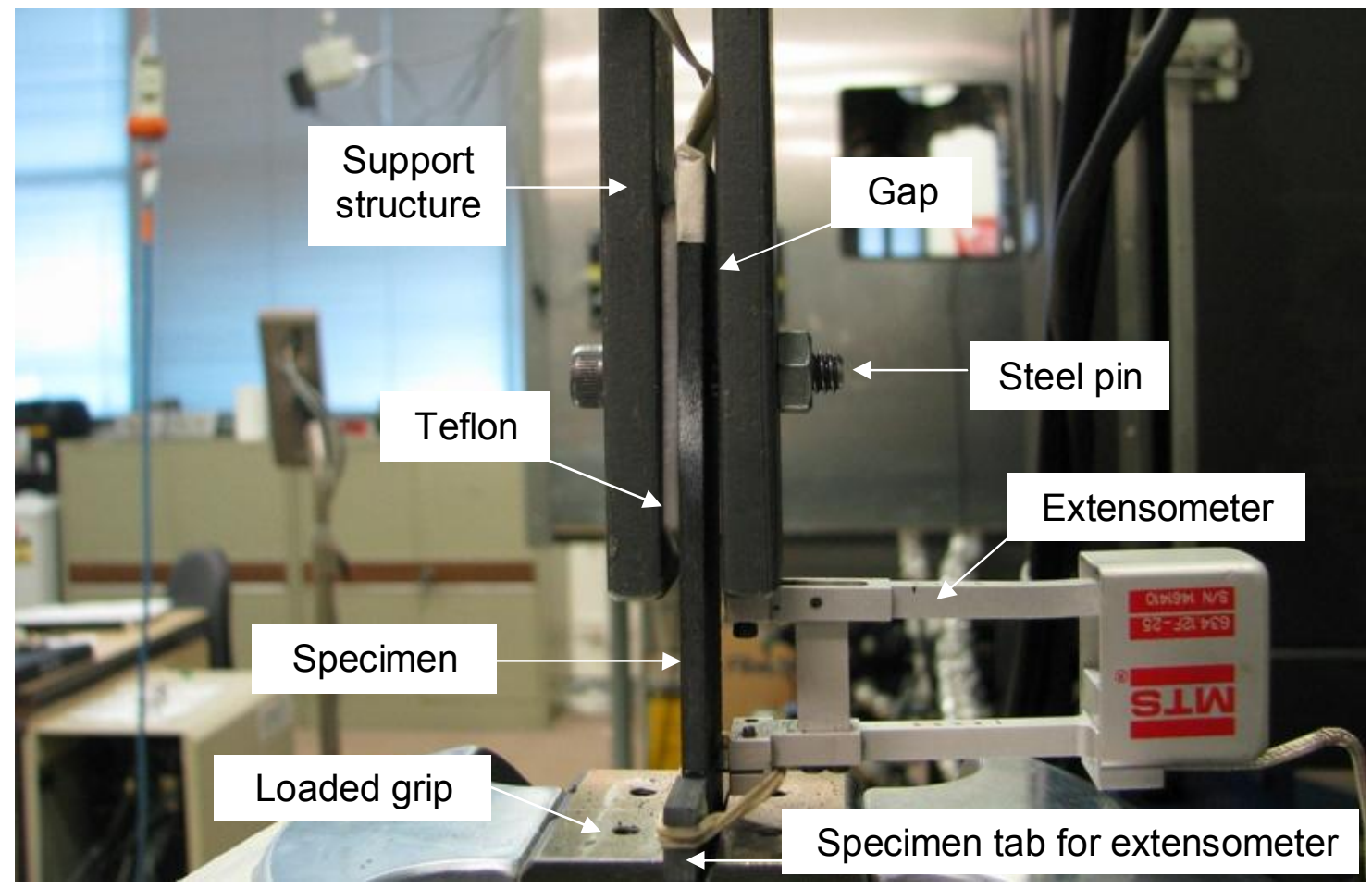

Figure 3: Bearing test experimental setup 


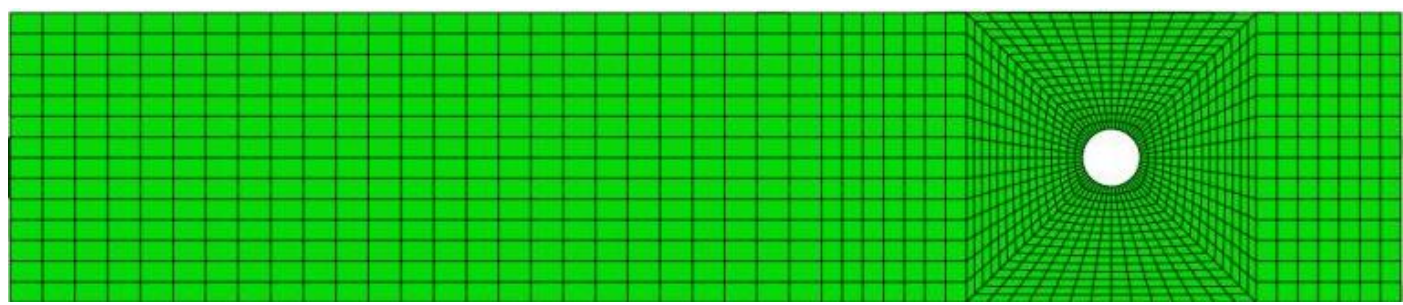

a

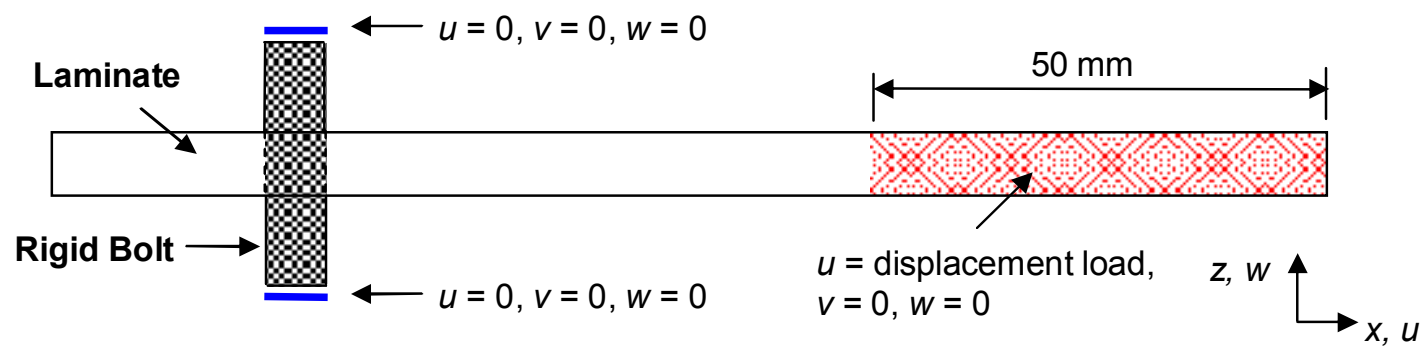

b

Figure 4: Bearing test. (a) In-plane mesh (b) Boundary conditions

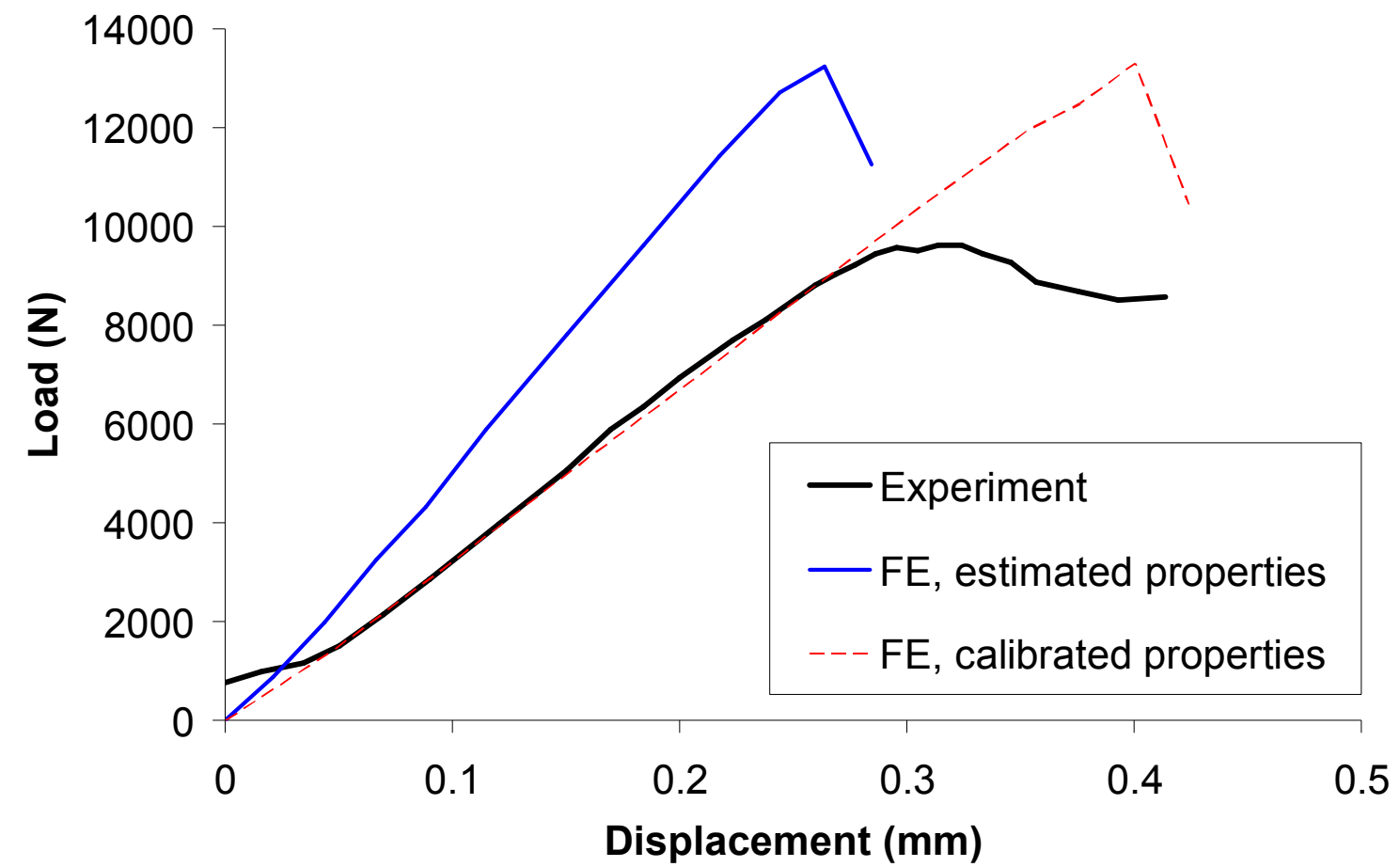

Figure 5: Calibration of ply properties using bearing test results up to bearing damage initiation 


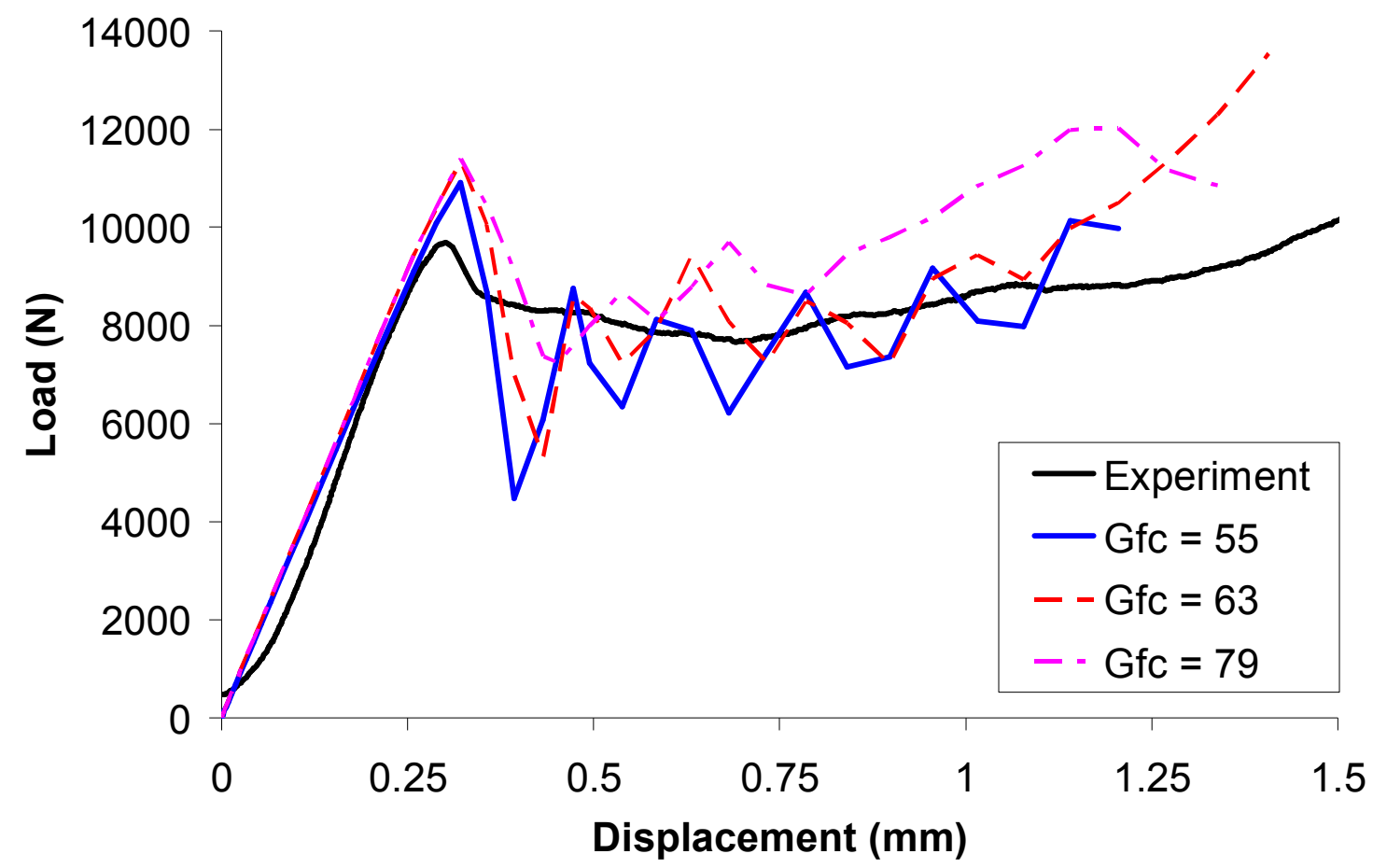

Figure 6: Bearing test, experiment and numerical with varying fibre compression fracture toughness $\left(\mathrm{kJ} / \mathrm{mm}^{2}\right)$.

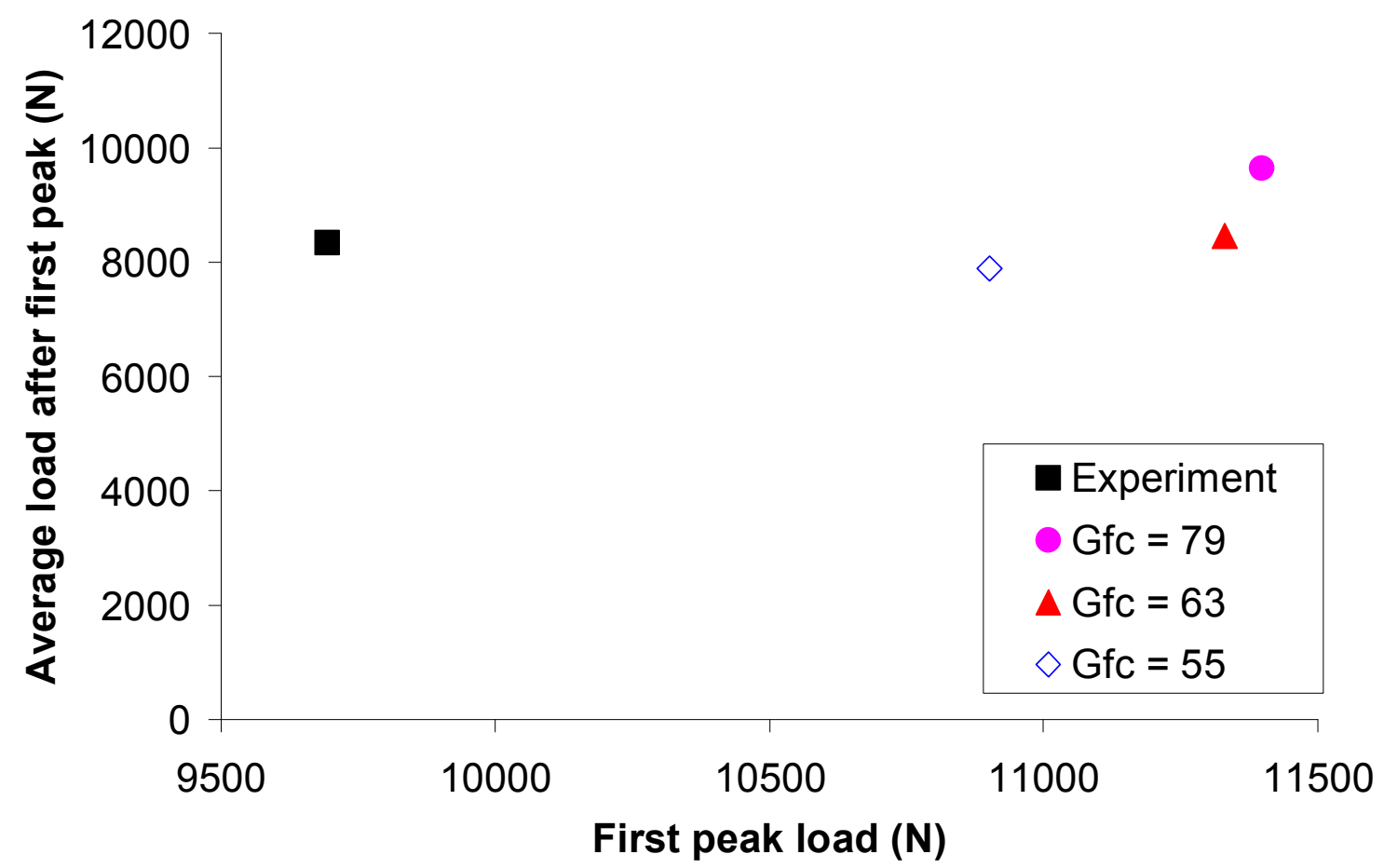

Figure 7: Bearing test, first peak load versus average load after first peak, experiment and numerical with varying fibre compression fracture toughness $\left(\mathrm{kJ} / \mathrm{mm}^{2}\right)$ 


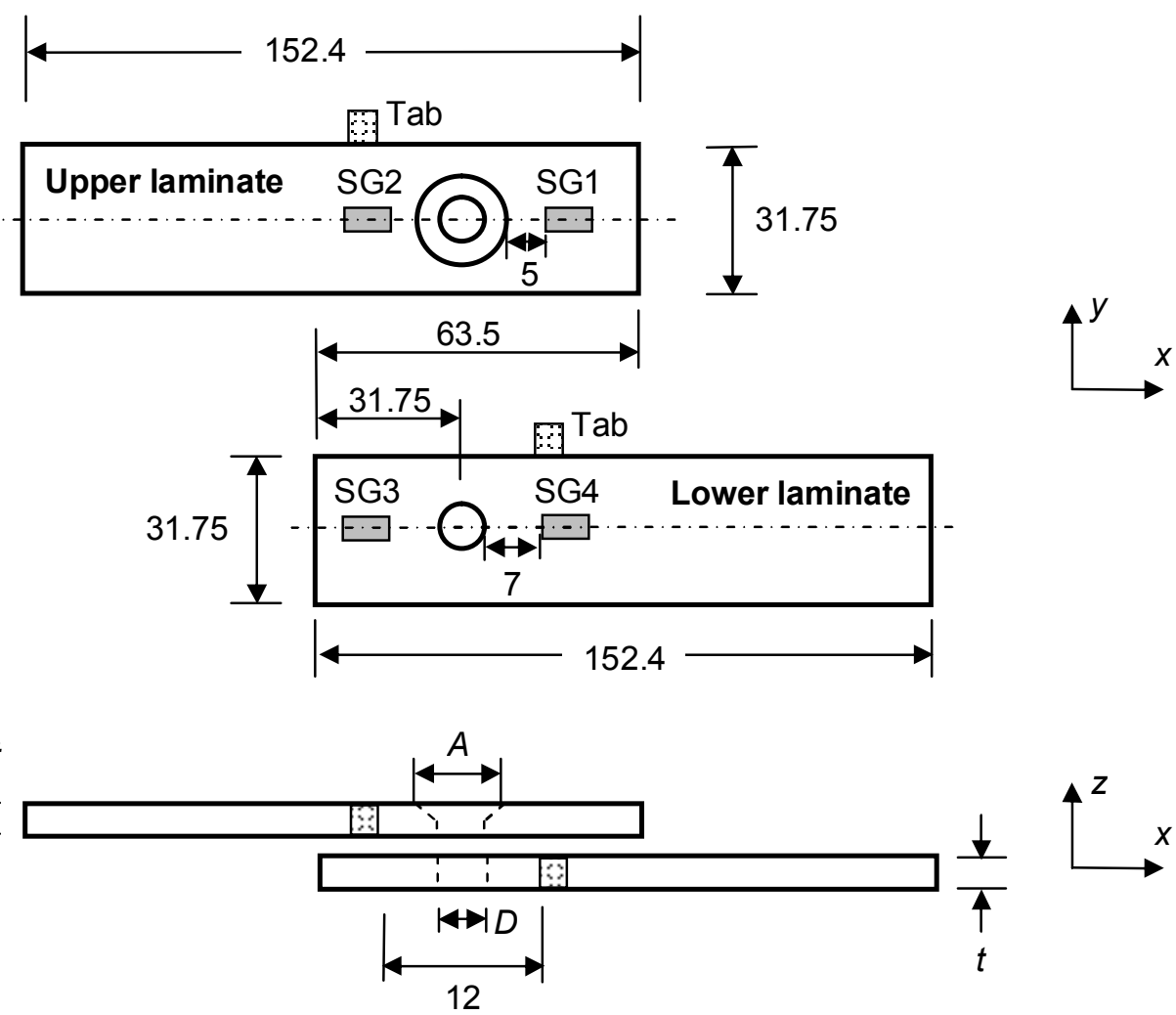

Figure 8: Countersunk joint dimensions ( $\mathrm{mm}$ ), strain gauge locations and extensometer tabs 


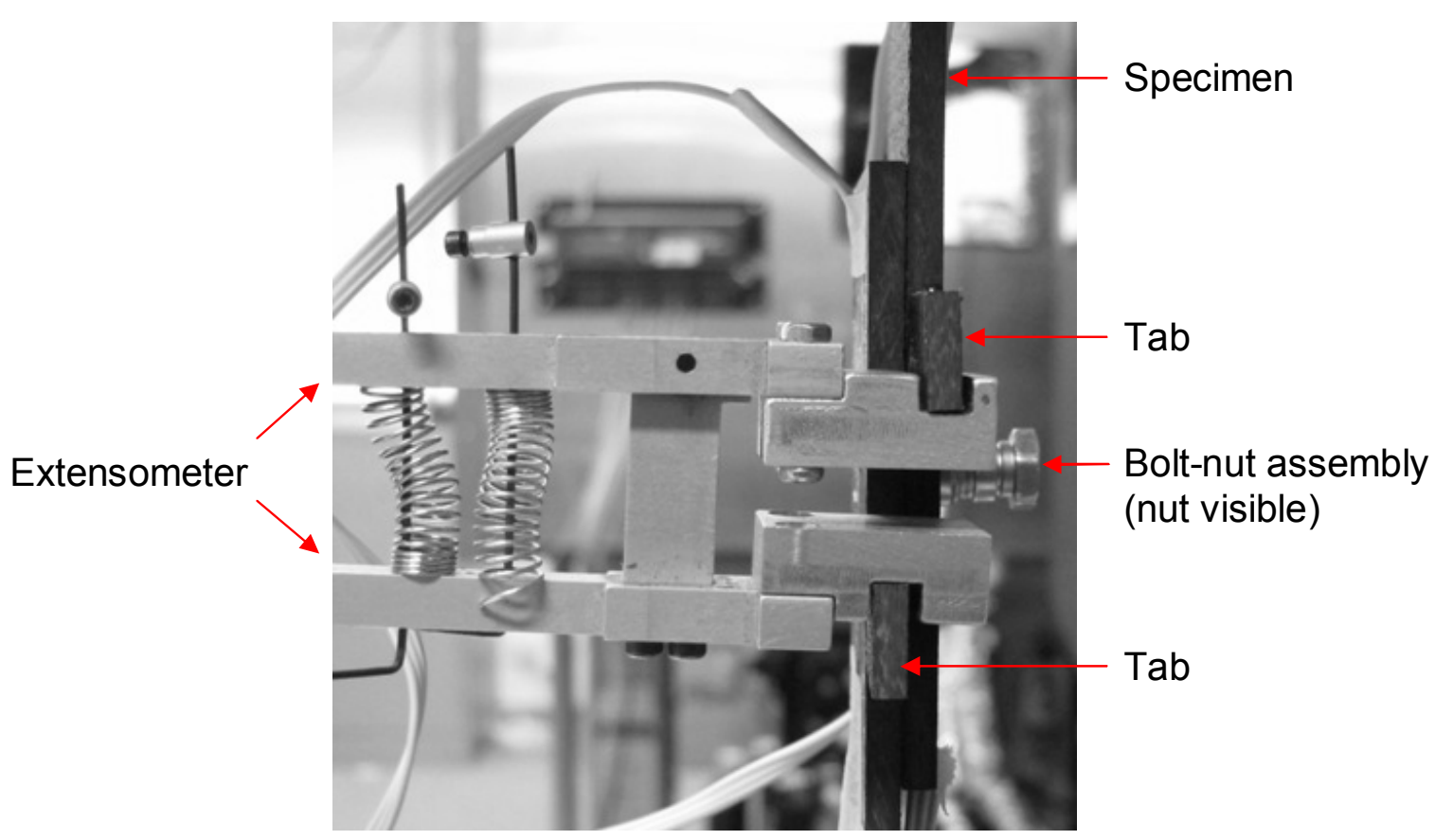

Figure 9: Experimental setup for the single-lap countersunk joints, joint region shown 


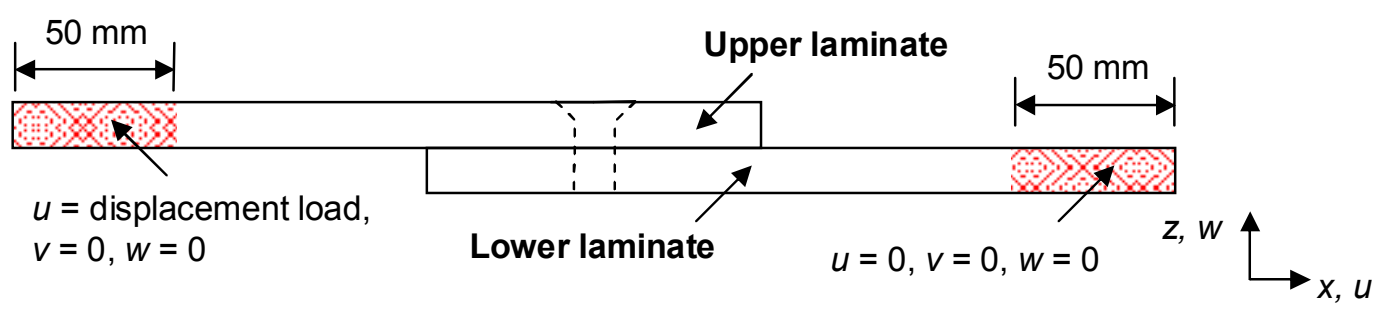

a

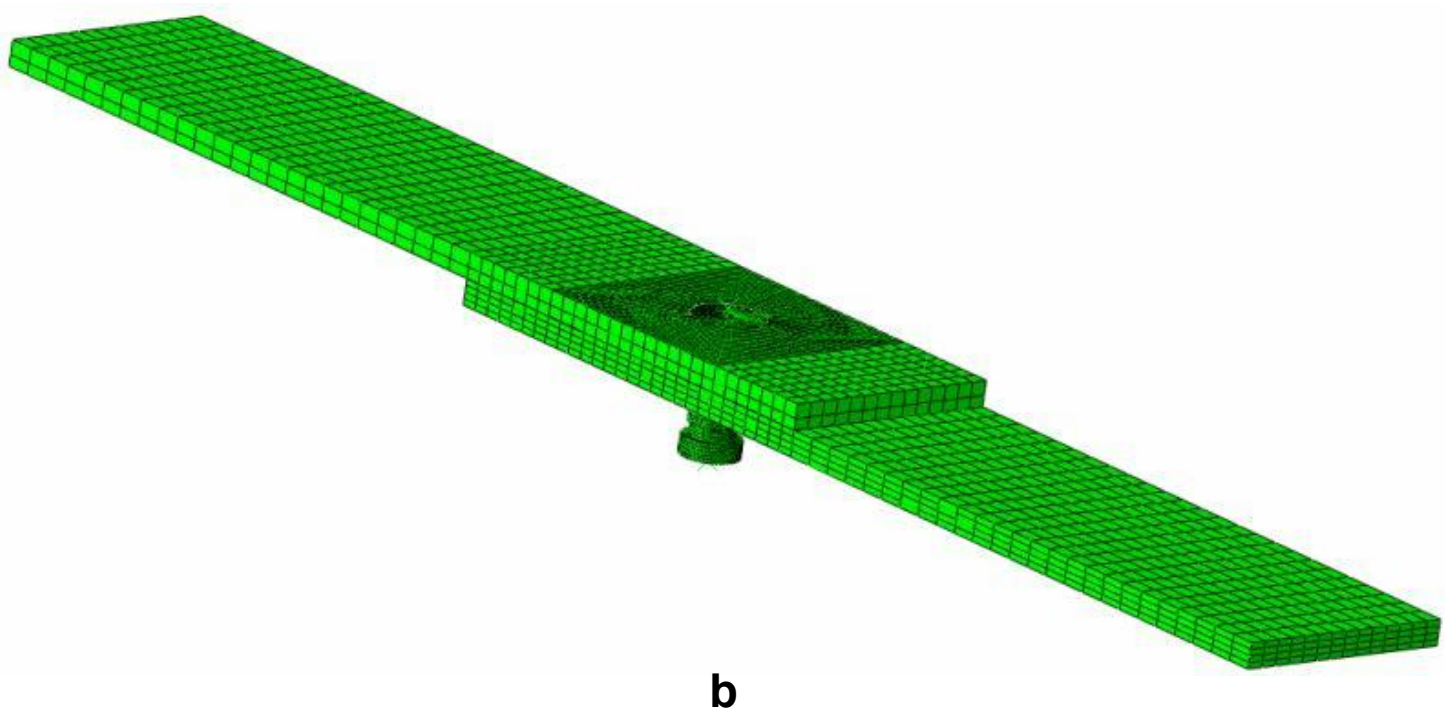

Figure 10: Single-lap joint. (a) Boundary conditions. (b) Assembled model. 


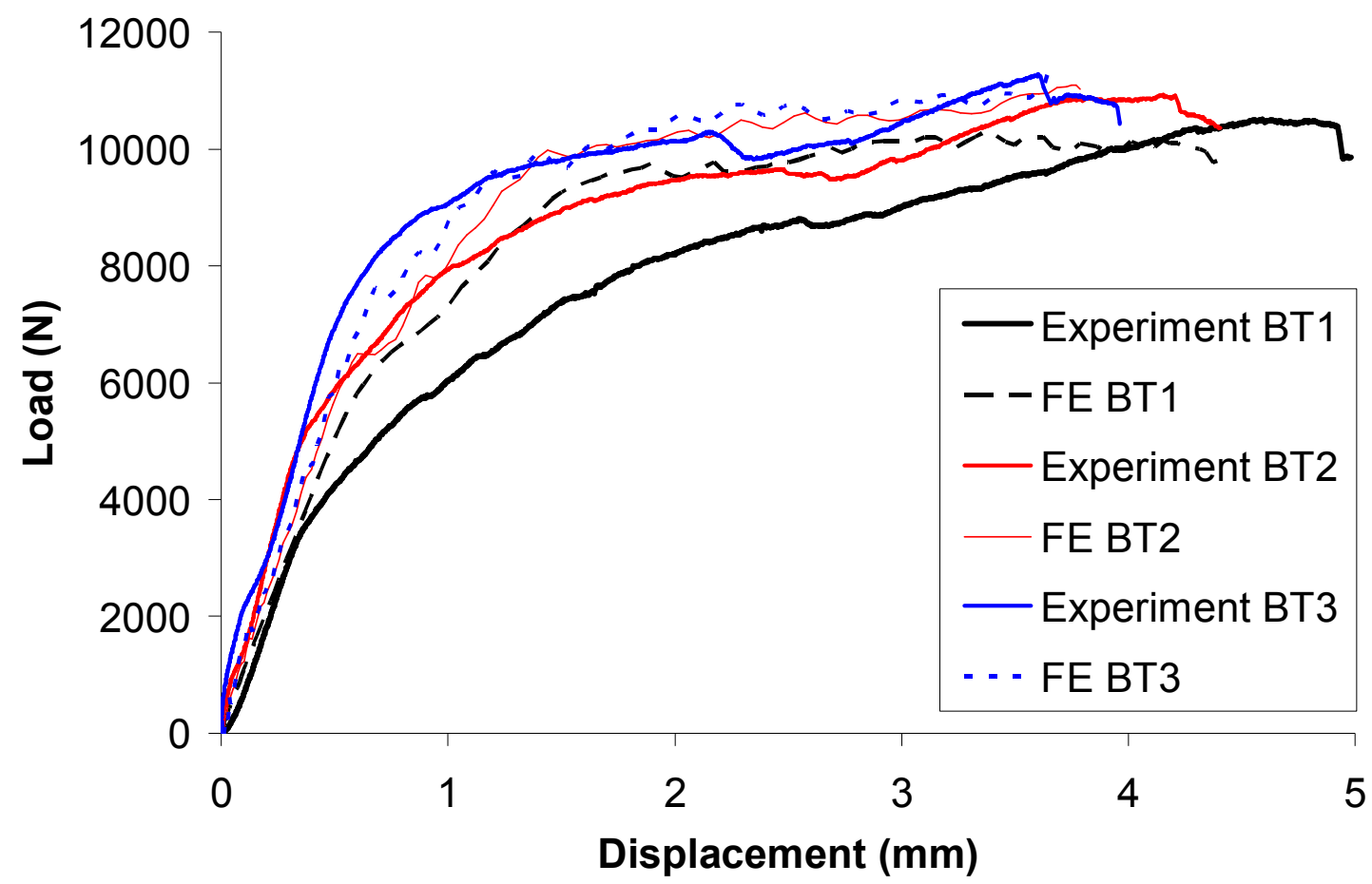

Figure 11: Single-lap joints, variation in bolt torque, experimental and numerical results

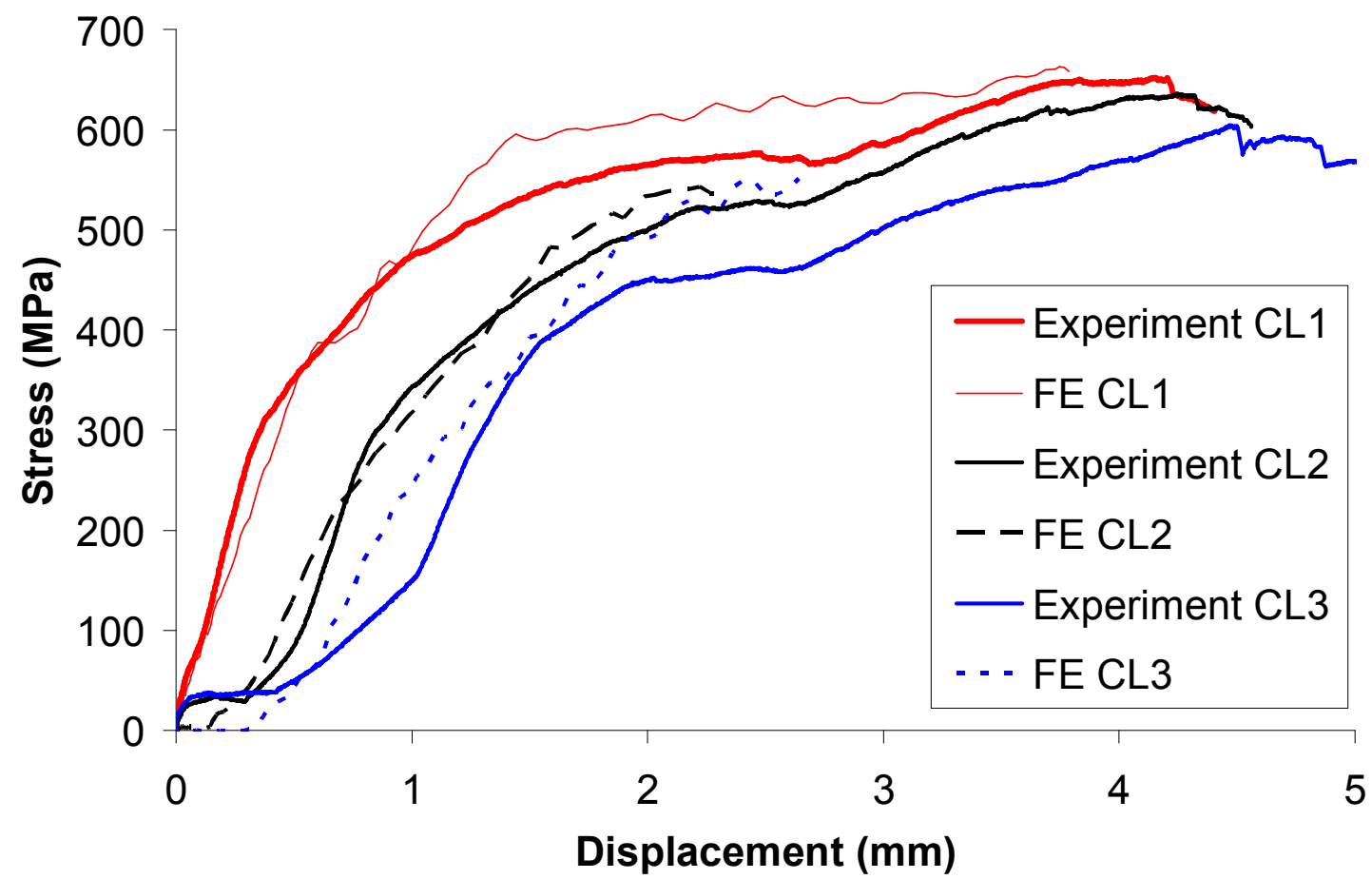

Figure 12: Single-lap joints, variation in clearance, experimental and numerical results 


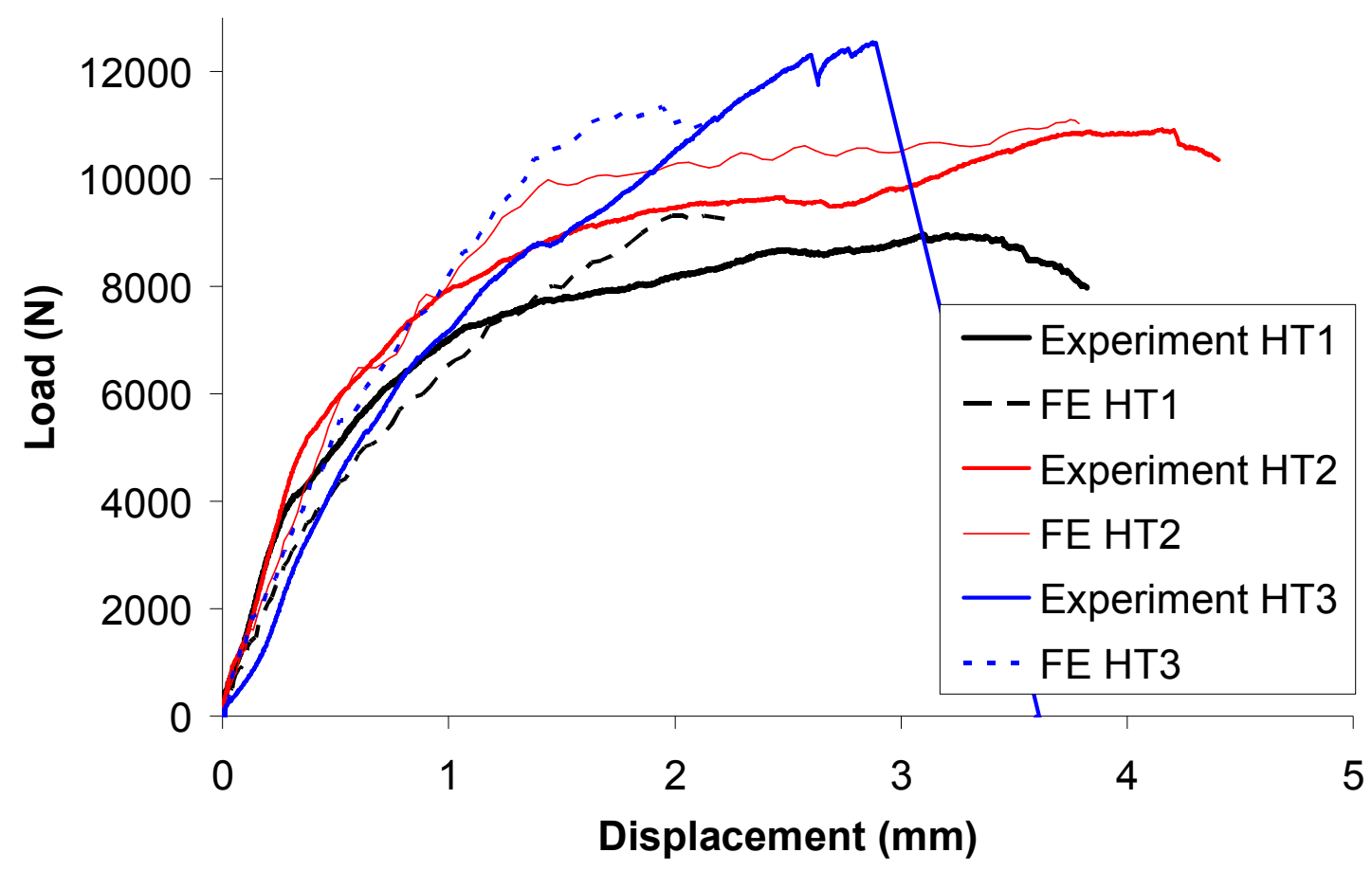

Figure 13: Single-lap joints, variation in countersink height ratio, experimental and numerical results

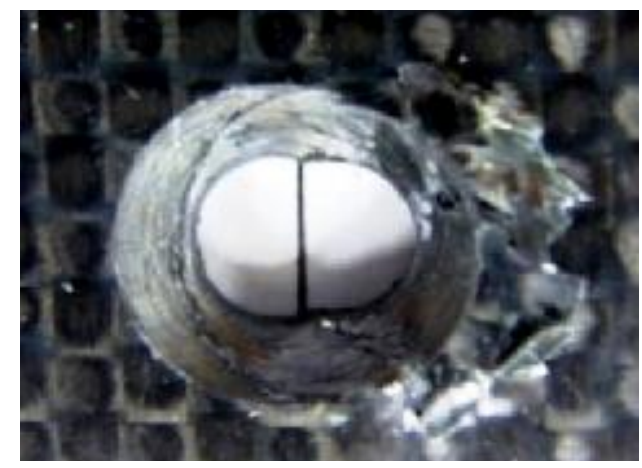

a

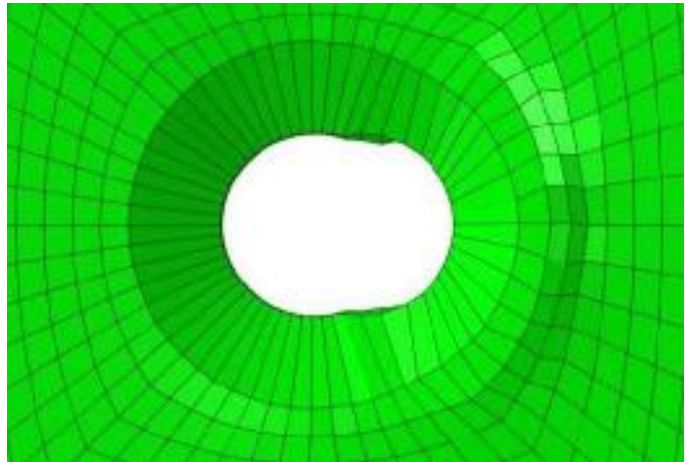

b

Figure 14: Single-lap joint (BT2, CL1, HT2) following ultimate load. (a) Experiment (b) Numerical model, deformed mesh 

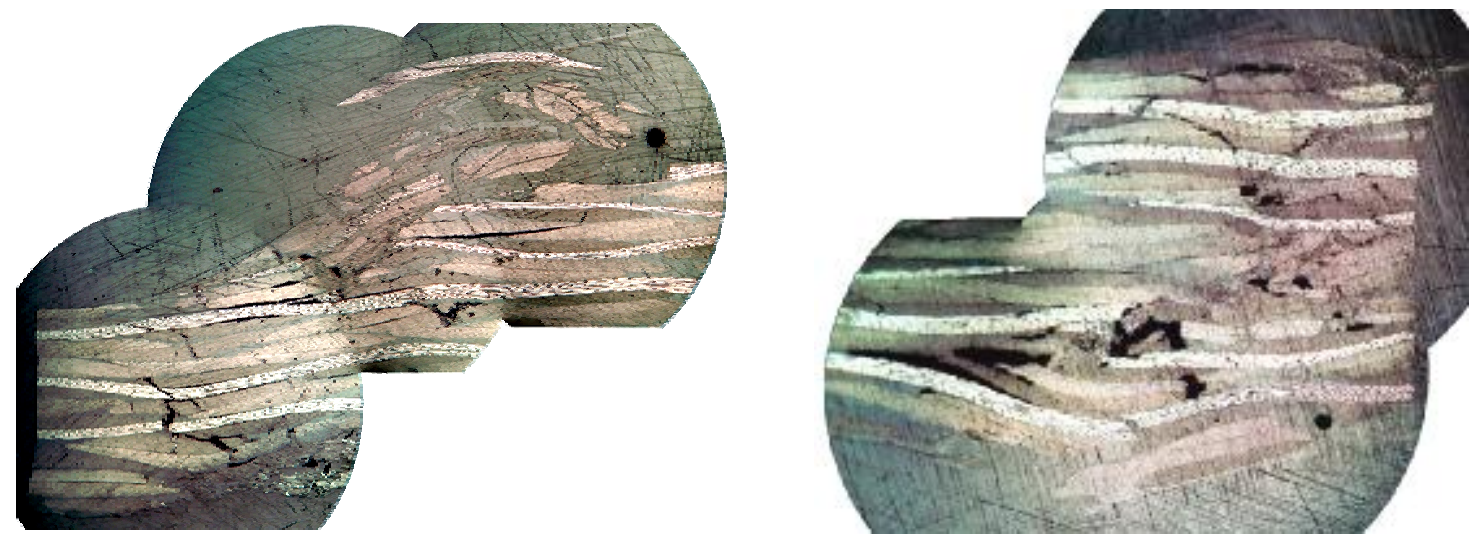

a
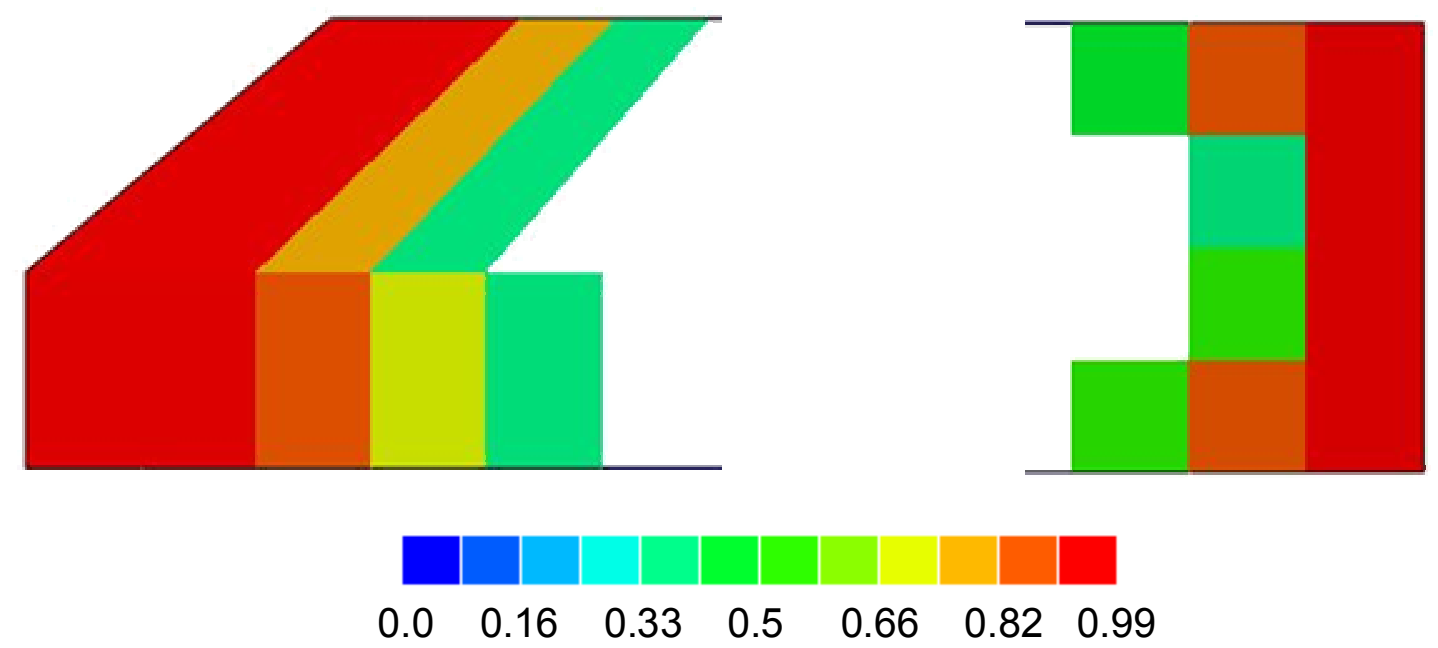

b

Figure 15: Single-lap joint (BT2, CL1, HT2) following ultimate load, cross-section at hole edge along specimen centreline. Left: Upper laminate. Right: Lower laminate. (a) Experiment (b) Numerical model, fibre compressive failure maximum damage index 